\title{
Argumentación y formación. Perspectivas para una sociedad democrática en la condición posmoderna ${ }^{1}$
}

\author{
Education and Argumentation. Perspectives for \\ a Democratic Society in the Postmodern Era
}

Sonia Cristina Gamboa Sarmiento ${ }^{2}$

\section{Resumen}

Este artículo plantea la democracia como forma de gobierno que es resultado del ejercicio de la democracia como forma de vida de los ciudadanos, quienes, por vía de la argumentación constituyen para sí mismos un conjunto de valores, a partir de los cuales conciben proyectos individuales y colectivos, al tiempo que impactan el entorno y lo transforman mediante la realización de estos proyectos. Se muestra, según las propuestas de Germán Vargas Guillén y Guillermo Bustamante Zamudio, que se requiere diseñar proyectos de formación para lograr ciudadanos para sociedades de estas características; y según las propuestas de Amartya Sen, Martha Nussbaum y Pierre Lévy, qué valores se necesita formar para realizar tales proyectos.

Palabras clave

Argumentación, formación, democracia, educación, pedagogía, condición posmoderna.

\section{Abstract}

This paper shows democracy as a way of Government that is the result of the exercise of democracy as the citizens' way of life. By means of argumentation they build for themselves a set of values, from which individual and collective projects are conceived. At the same time, they impact their environment and transform it through the implementation of these projects. According to the proposals of Germán Vargas Guillén and Guillermo Bustamante Zamudio, it is necessary to design citizens' formation projects for societies with these features. According to Amartya Sen, Martha Nussbaum and Pierre Lévy, the question is what values are required to educate subjects who will be able to make such projects a reality.

Key words

Argumentation, education, democracy, pedagogy, postmodern condition.

Artículo recibido el 26 de febrero de 2014 y aprobado el 20 de agosto de 2014

1 Este estudio hace parte de los desarrollos teóricos que fundamentan la investigación "Modelo de procesamiento de información para archivo de fenomenología y hermenéutica", financiada por la Universidad Industrial de Santander, con el código 5573. A partir de este desarrollo, la investigación busca establecer el archivo digital como dispositivo de formación para la construcción de una sociedad democrática.

2 Universidad Industrial de Santander, Bucaramanga, Colombia. Correo electrónico: scgamboa@uis.edu.co 
Los ideales de la democracia parecerían retomar vigencia en una sociedad necesitada cada vez más del reconocimiento de los derechos fundamentales, del valor de lo público, del respeto por la diferencia. Si se entiende la democracia no solo como la posibilidad de ejercer el derecho al voto, sino como una forma de gobierno que le garantiza a sus ciudadanos la posibilidad de ejercer y exigir el cumplimiento de los derechos fundamentales, de las leyes, el derecho a la educación, a la salud, a la seguridad social, se requiere, entonces, que estos ciudadanos se constituyan como sujetos racionales, sujetos de derechos, que estén en capacidad de autoexaminarse críticamente, de comprender y de respetar las condiciones culturales e históricas de los demás, de intervenir en escenarios de debate, en el diseño o el replanteamiento de las políticas públicas.

Todo ello parece posible por vía de la argumentación, para la cual se requiere, de una parte, la formación de sujetos con sólidas estructuras argumentativas, que puedan reconocer, construir y pronunciar discursos persuasivos sobre la base del pensamiento racional; de otra parte, se requiere de entornos que resulten naturales o familiares para los sujetos, en los que se pueda propiciar el debate, el intercambio de ideas, el respeto por el otro.

Los entornos virtuales, el ciberespacio de P. Lévy, parecería ser el medio para volver a una democracia participativa, para pensar y discutir proyectos en los que esté implicado el bien común, sin los límites espaciales que determina la corporalidad, más allá de las fronteras que definen los Estados. Pero, ¿son, realmente, las redes sociales espacios de argumentación? Si se trata de pensar proyectos propios y de defenderlos, reformularlos, corregirlos, en diálogo con los otros, un espacio de argumentación debería proporcionar elementos, propiciar condiciones y contribuir a formar los valores para que ella pueda darse.

\section{El contexto sociopolítico}

El poder del dinero, combatido con fuerza por la Resistencia, no ha sido nunca tan grande, tan insolente y tan egoísta con sus propios servidores, incluso en las más altas esferas del
Estado. [...] la brecha entre los más pobres y los más ricos no ha sido nunca tan grande, ni la búsqueda del dinero tan apasionada.

(Hessel, 2011 p. 4)

La sociedad actual está determinada por convergencia de fenómenos como el capitalismo; la globalización; el avance acelerado de la tecnología electrónica y digital; la prevalencia, en la educación, en la investigación y los servicios de salud, de criterios como calidad, por encima de la formación, el conocimiento y la vida misma; el contraste político y cultural entre grupos de valores conservadores y movimientos que promueven la libertad de cultos, de orientación sexual, el respeto por la vida, por los animales, por los recursos naturales, entre otros aspectos. Todos ellos parecerían corresponder a "las transformaciones que han afectado a las reglas de juego de la ciencia, de la literatura y de las artes a partir del siglo XIX" (Lyotard, 2008, p. 4), lo que Lyotard definió como la condición postmoderna.

El capitalismo, la globalización, la producción de patentes y la innovación tecnológica, como elementos determinantes de los sistemas económicos que prevalecen en occidente, han contribuido a mejorar la calidad de vida de los "propietarios", generalmente ubicados en los países centrales o en el "centro", mientras los países periféricos o la "periferia", en donde generalmente se ubica la fuerza de trabajo y los recursos naturales inexplotados para la producción de capital, siguen teniendo problemas sociales como altos índices de natalidad, de muerte por desnutrición o epidemias, y analfabetismo, así como deforestación, devastación de ecosistemas, etc.

Al margen de las políticas nacionales que permiten la explotación de los recursos naturales, que afectan las condiciones de bienestar de los ciudadanos, el Nobel de economía Amartya Sen plantea la necesidad de que las culturas de la periferia no se resistan al fenómeno de la globalización tanto de las ideas como de las prácticas científicas y tecnológicas. Paradójicamente, no siempre los más necesitados, los marginados, lo son por escasez de recursos, sino tal vez por falta de conocimiento en "cómo hacer un 
buen uso de las importantes ventajas del intercambio económico y el progreso tecnológico" (Sen, 2006, p. 104) y en cómo reclamar y hacer valer sus derechos fundamentales y sus derechos a la seguridad social. Así, con independencia de cuál sea el origen de los problemas sociales de la periferia, su permanencia parece más relacionada con una carencia de habilidad para aprovechar sus ventajas:

No es posible revertir la penuria económica de los pobres a lo largo y ancho del mundo manteniéndolos al margen de los avances tecnológicos actuales, la probada eficiencia del intercambio yel comercio internacionales y los beneficios sociales y económicos que se derivan de vivir en una sociedad abierta. (Sen, 2006, pp. 103-104)

Por otra parte, en la condición posmoderna la ciencia ya no parece estar justificada solo por la búsqueda del conocimiento en sí misma, como su principal forma de legitimación, sino por la performatividad, que responde, según Lyotard, a la idea capitalista de orientar la investigación y la enseñanza a la eficiencia de los sistemas económicos estatales; es decir, le ha dado al saber científico un valor de cambio, que depende más de su eficiencia que de la búsqueda de la verdad o de la justicia como formas de legitimación, criterios que quedan circunscritos a sistemas de conocimiento locales (cf. Lyotard, 2008, p. 44).

De tal forma que se privilegia financiar la investigación aplicada o finalizada, que "es una investigación autoritariamente programada, orientada, organizada con vistas a su utilización [...] ya se trate de técnica, de economía, de medicina, de psicosociología o de poder militar", tal como lo expone Derrida (1997, p. 9), sobre la investigación fundamental o desinteresada, pues su preocupación gira en torno al "conocimiento, la verdad, el ejercicio desinteresado de la razón, bajo la sola autoridad del principio de razón" (Derrida, 1997, p. 9).

Las dinámicas de investigación financiada por el Estado, según sus intereses, se orienta a la producción de patentes, a resultados que puedan ser comercializados o aplicados, a formar estudiantes en competencias científicas y tecnológicas, a almacenar, procesar y producir grandes volúmenes de datos que puedan representar información relevante para la ciencia, para la inteligencia militar y para fines comerciales. Estas investigaciones son necesariamente realizadas por equipos interdisciplinarios que puedan responder a los problemas de investigación e innovación planteados.

La globalización, por su parte, ha propiciado fenómenos de migración que hacen que las culturas no sean totalmente regionales, al tiempo que ciertas costumbres, hábitos, productos, lenguas, creencias religiosas o espirituales van adquiriendo un carácter más universal. Así mismo, los sujetos, en cuanto se abren a nuevas posibilidades culturales,van adquiriendo la condición de ciudadanos del mundo, en el sentido que, según Martha Nussbaum, lo manifestó el filósofo griego Diógenes, en cuanto “[...] se negaba a definirse simplemente por sus orígenes locales y por su calidad de miembro de un grupo [...]. Insistió en definirse en función de aspiraciones y preocupaciones más universales" (Nussbaum, 2001, p. 81), y que luego acogieron los estoicos como "kosmopolites o ciudadanos del mundo, argumentando que, en efecto, cada uno de nosotros habita en dos comunidades: la comunidad local de nuestro nacimiento, y la comunidad del razonamiento y aspiraciones humanas" (p. 82).

Esta condición exige, según Nussbaum, el cultivo de la humanidad, que consiste en que los sujetos se formen en valores como un continuo autoexamen crítico, comprensión, tolerancia, respeto; y en temas como historia, lenguas y costumbres de otras culturas; lo que constituye "una educación que es liberal', en cuanto libera la mente de la esclavitud de los hábitos y la costumbre, formando personas que puedan actuar con sensibilidad y agudeza mental como ciudadanos del mundo" (Nussbaum, 2001, p. 28).

Las circunstancias expuestas, así como la necesidad del cultivo de la humanidad, muestran que la democracia, entendida como discusión pública, parece ser la forma de gobierno más adecuada para que los ciudadanos puedan ejercer la política, participar en las decisiones que los afectan, promover nuevas ideas y proyectos. Amartya Sen propone la democracia como un valor universal, partiendo del 
reconocimiento de que a lo largo de la historia occidental y no-occidental las ideas democráticas han estado presentes como forma de gobierno, y que las mismas se han consolidado en el siglo XX como la forma de gobierno por excelencia:

Entre la gran variedad de acontecimientos ocurridos durante el siglo XX, no encuentro dificultad alguna en elegir uno como fundamental: el ascenso de la democracia [énfasis del original]. [...] creo que en un futuro [...] no habrá dudas en aceptar la primacía de la emergencia de la democracia, que ha constituido, de manera muy notable, la única forma aceptable de gobierno. (Sen, 2006, p. 56)

\section{Democracia: política, ética e inteligencia colectiva}

\begin{abstract}
Por ser la democracia una educación con inteligencia colectiva, por ser capaz de movilizar, de valorizar y de emplear lo mejor posible todas las cualidades humanas, ella es, en tiempo real, el régimen político más apropiado para conceder la eficacia y la potencia característica del siglo XXI.
\end{abstract}

(Lévy, 2004, p. 54)

Si se entiende por democracia una forma de gobierno que ofrece "la posibilidad de que los ciudadanos participen en el debate político y, con ello, de estar en disposición de influir en las opciones relativas a los asuntos públicos" (Sen, 2006, p. 12), una sociedad democrática debería garantizar no solo el derecho al voto, sino:

[...] el respeto del mismo en los resultados electorales; [...] la protección de la libertad, el respeto de los derechos dentro del marco legal y la garantía de la libertad de expresión; [...] que no exista censura de prensa y que la información pueda circular libremente. [Que en las elecciones] las diferentes partes [...] cuenten con la oportunidad adecuada de presentar sus puntos de vista y sus programas, [que] el electorado [goce] de libertad para informarse y considerar los planteamientos de los contendientes. (Sen, 2006, pp. 72-73)
Sen concibe, además, la idea de democracia como un valor universal, pues muestra cómo en sociedades en las que los sujetos toman conciencia de sus derechos fundamentales, políticos y civiles, discuten, reclaman por ellos y someten a críticas las políticas gubernamentales, se ha contribuido a la prevención y a la solución de problemas sociales y económicos:

La respuesta de un gobierno al sufrimiento de su gente depende en buena medida de la presión que se ejerce sobre él. El ejercicio de los derechos políticos (como el voto, la crítica y la protesta, entre otros) puede establecer una diferencia real e influir profundamente en la actuación del gobierno en cuestión. (Sen, 2006, p. 66)

La práctica de la democracia representa un factor de impacto sobre los sujetos, sobre su vida y sus decisiones, así como sobre la sociedad misma. Por una parte, la conciencia de libertad política permite a los sujetos entender y reclamar sus derechos en pro de una vida mejor; por otra parte, la participación política se constituye en un mecanismo para que los ciudadanos hagan saber sus demandas y necesidades, lo que, en consecuencia propicia el diálogo entre ciudadanos, la formación de valores y la concepción y ejecución de proyectos que satisfagan necesidades sociales e individuales (cf. Sen, 2006, pp. 73-74).

La democracia se corresponde así con una práctica intersubjetiva, organizada, ética, en la que se potencian las capacidades individuales para pensar lo colectivo. Pierre Lévy ha denominado esta forma de organización colectivos inteligentes, conformados por "sujetos cognitivos abiertos, capaces de iniciativa, de imaginación y de reacción rápidas" (Lévy, 2004, p. 13), que llegan a impactar, mediante la deliberación, las reglas de convivencia, de respeto, de tolerancia, así como las políticas sobre el cuidado de lo público, de los recursos naturales, etc. La democracia ofrece a los sujetos la oportunidad de participar activamente de la vida en comunidad; de construir permanentemente su identidad política en la medida que contribuye a la solución de problemas de su interés, para los que adopta posiciones y aporta argumentos. Sobre la democracia, Lévy sostiene: 
Este régimen político es el menos malo, no porque otorgue el poder a una mayoría tomada en su conjunto, sino porque moviliza un pensamiento colectivo para el gobierno de la ciudad. No se le prefiere porque establezca el dominio de una mayoría sobre una minoría, sino porque limita el poder de los gobernantes y porque instituye recursos contra la arbitrariedad. ¿Es la democracia la más agradable de las constituciones porque otorga el poder a los representantes del pueblo? No por ello, sino únicamente en la medida en que reemplaza las reglamentaciones particulares, los privilegios y los monopolios, por mecanismos generales de regulación. Somos demócratas porque este régimen limita el poder al mínimo necesario para hacer que se respete el derecho. (Lévy, 2004, pp. 55-56)

Queda, entonces, por considerar cómo se desarrollan tales capacidades individuales para pensar lo colectivo; si su despliegue deviene naturalmente en el ejercicio del debate, de la argumentación, o si es necesario concebir proyectos de formación que contribuyan a potenciarlas, a orientarlas. $M$. Nussbaum plantea que cultivar la humanidad consiste en contribuir a desarrollar en los ciudadanos tres características:

1. La habilidad para el examen crítico de uno mismo, en el sentido socrático de vida examinada, entendida como la habilidad para razonar lógicamente acerca de la coherencia, la validez lógica, la solidez del razonamiento, la exactitud de los hechos y la precisión del juicio, en cuanto a creencias, tradiciones e ideas antes de aceptarlas (cf. Nussbaum, 2001, p. 29).

2. Dado el carácter internacional y multicultural del mundo actual, la capacidad de reconocerse como de determinada región o grupo, pero también como "seres humanos vinculados a los demás seres humanos por lazos de reconocimiento y mutua preocupación" (Nussbaum, 2001, p. 30); reparar no solamente en lo que nos hace semejantes como género humano, sino en lo que nos hace diferentes de los otros, individual y colectivamente.

3. La imaginación narrativa que consiste en la capacidad de pensar cómo sería estar en el lugar de otra persona; ser un lector inteligente de la historia de esa persona, y comprender las emociones, deseos y anhelos que alguien así pudiera experimentar" (Nussbaum, 2001, pp. 3031); esta capacidad permite que al confrontar las creencias y los juicios propios con los de otros se actúe de manera responsable en el intento de "ver el significado de una acción según la intención de la persona que la realiza. (Nussbaum, 2001, p. 31)

Estos tres enfoques muestran que la democracia como forma de gobierno es resultado del desarrollo de un conjunto de valores y de capacidades individuales, que se propician y se realizan en entornos sociales, de manera que devienen valores y capacidades colectivas, pero también proyectos y obras comunes, que impactan el sentido de lo público. Se repara, entonces, en la necesidad de que los sujetos aprendan a pensar lógicamente, a exponer sus puntos de vista, a respetar los de los demás, a discutir sin violencia. La argumentación parecería ser la vía más adecuada para lograr este objetivo; para ello se requiere propiciar su aprendizaje y su práctica.

\section{La argumentación como alternativa de formación para la democracia}

\begin{abstract}
La naturaleza misma de la deliberación y de la argumentación se opone a la necesidad y a la evidencia, pues no se delibera en los casos en los que la solución es necesaria ni se argumenta contra la evidencia.
\end{abstract}

(Perelman y Olbrechts-Tyteca, 2006, p. 30)

Se entiende aquí la argumentación como la estructura formal de todo discurso elaborado con el fin de persuadir, por medios no-coactivos, a una audiencia con determinadas características, acerca de una determinada tesis o afirmación. Podría decirse que el ejercicio de la argumentación se requiere en todos los ámbitos de la vida en los que los sujetos interactúan con otros, incluso consigo mismos; en la vida familiar y social, el periodismo, la política, la comunicación, etc. Puede afirmarse, incluso, que 
la argumentación es una de las estructuras de la interacción comunitaria, de la vida intersubjetiva.

La argumentación se hace necesaria en circunstancias en las que se requiere sostener una tesis o afirmación sobre temas que, por su naturaleza, no permiten llegar a conclusiones necesarias, verdaderas o que constituyan una certeza, puesto que en tales temas está implicado el juicio o asentimiento de quienes hacen las veces de auditorio. En tales circunstancias, dado que no es posible mostrar evidencias, se requiere apelar a técnicas que permitan logran la adhesión de los otros a las tesis presentadas. Estas técnicas se fundan en las pruebas de persuasión que Aristóteles clasificó en tres especies: las del talante del orador, las de la disposición del oyente y las del discurso (cf. Retórica I, 2, 1356a 1-4). Tanto la Retórica de Aristóteles como su posterior interpretación por Perelman y Olbrechts-Tyteca, en el Tratado de la argumentación (2006), están enfocados en describir las estructuras del discurso; sin embargo, el oyente, el auditorio, se constituye en una variable que tiene que ser considerada desde un punto de vista ético, pues se trata de reconocer en este oyente el carácter de sujeto que exige respeto, al que no se puede someter a engaño, a coacción, a violencia, a seducción, con el fin de que se adhiera a las tesis objeto de la argumentación; sea este de cualquiera de los tres tipos definidos por Perelman y Olbrechts-Tyteca (2006, p. 70): auditorio universal, interlocutor único o el propio sujeto.

Es necesario, en el ejercicio de la ciudadanía, tener en cuenta que a pesar de que un discurso esté construido de manera lógica y persuasiva a la vez, quien está en posición de oyente lleva consigo conocimientos, costumbres y creencias que deben ser respetados. La imaginación narrativa como una de las formas del cultivo de la humanidad reclama la necesidad de no usar a los demás como "instrumento para un fin público" (Nussbaum, 2001, p. 123), sino de procurarla "formación de una ciudadanía donde priman la decencia y las opciones públicas fundamentales" (Nussbaum, 2001, p. 123). Para Nussbaum, "aunque el bien común no debe ser descuidado, flaco servicio se le habrá prestado a este bien si los seres humanos son vistos como simples instrumentos para los propósitos del otro" (Nussbaum, 2001, p. 123).

Las estructuras formales de la argumentación y retórica se centran en la descripción de las habilidades del orador, la construcción del discurso y las formas adecuadas de persuadir al auditorio; pero la democracia exige, además, tener en cuenta que el auditorio, como objetivo de la argumentación, no solamente escucha, también piensa, responde, tiene sus propias opiniones e intereses: su propio discurso. La argumentación y la retórica podrán ser considerados, entonces, como procesos completos en la medida que el auditorio esté en posibilidad de responder con un nuevo discurso que, a su vez, involucre las habilidades y variables ya mencionadas.

En la perspectiva de la democracia como debate público es claro que conviene que todos los ciudadanos estén en capacidad de mantener una mirada crítica sobre las políticas públicas de Estado, con el fin de defender los derechos civiles y el cuidado del bien común, pues

\section{[...] intentar resolver los defectos de la práctica} democrática a través del autoritarismo y la suspensión del debate público [...] incrementa la vulnerabilidad de un país ante desastres esporádi$\cos [\ldots]$ actúa en detrimento de las ventajas conquistadas con anterioridad, debido a la ausencia de una vigilancia pública [...]. (Sen, 2006, p. 50)

Esta perspectiva de la democracia muestra la necesidad de que los ciudadanos, en su mayoría, cuenten con habilidades argumentativas para evaluar críticamente los discursos o los argumentos de los demás; y que, en consecuencia, los sujetos no asuman la posición de ser persuadidos por otros, sino de persuadirse a sí mismos. De este modo, si se considera que "un país no tiene que considerarse como adecuado o preparado para la democracia; en lugar de eso, tiene que volverse adecuado mediante la democracia" (Sen, 2006, p. 58), el ejercicio de la democracia no empieza en el espacio público, en el sentido propuesto por Hanna Arendt, es decir, en el ejercicio de la política, o en la mayoría de edad, sino en entornos en los que se busque promover la 
democracia como valor individual y colectivo, en proyectos de formación que promuevan el aprendizaje de las leyes y normas estatales y mundiales; el aprendizaje y el respeto por las creencias, por el lenguaje, por los propósitos comunes de la propia y de otras culturas; y la argumentación con herramienta para formar una visión crítica de las posiciones propias y ajenas. El ámbito de desarrollo de tales proyectos podría ser ambientes escolarizados y no-escolarizados, así como ambientes cotidianos.

\section{Formación y efectos de formación}

La pedagogía, entendida como formación, consiste en:

[...] un problema filosófico del sentido con el que los seres humanos dan contenido a sus horizontes de ser, en la construcción de proyectos individuales y colectivos. [...] un proyecto agonal cuya lucha radica en persuadirse los sujetos, unos a otros, de los valores, de los caminos para su realización, y del respeto y de la tolerancia que exige la construcción del sentido del mundo personal en el contexto político con los otros. (Vargas Guillén, Gamboa Sarmiento, y Reeder, 2008, p. 59)

La pedagogía comprende un conjunto de condiciones que posibilitan y promueven la formación de las personas mediante la persuasión, en proyectos colectivos en los que tienen la oportunidad de ver sus propios horizontes y realizarlos en contextos de intersubjetividad.

La formación, por su parte,

[...] es empoderamiento del sujeto [énfasis del original]. Se trata de que cada quien se tome por sí mismo la responsabilidad del mundo, su sentido; pero, simultáneamente, para que ello ocurra, es imperativo que cada quien ejerza la crítica de todo lo dado por la tradición. (Vargas Guillén, 2012, p. 49)

De manera que tal formación se forme a partir de los elementos que le ofrece la cultura mediante el sentido que le da a tales valores, pero que, al tiempo, con la resignificación que hace de estos valores, forme la cultura, forme su entorno, lo transforme. La formación consiste, entonces, en formarse, en cons- tituirse como sujeto a partir de un sentido crítico de las vivencias propias y de la conciencia de estar formándose, de estar llevando a cabo este proceso.

Principalmente, los sujetos se forman en el encuentro consigo mismos, cuando realizan un paso de la percepción natural del mundo, de la vivencia cotidiana de experiencias, a la percepción consciente de sí mismos, a la apercepción. Es en este proceso que el sujeto da sentido a sus vivencias, constituye sentido de las mismas. También el sujeto se hace consciente de sí en el diálogo intersubjetivo, consigo mismo y con los demás.

La formación consiste, entonces, en un proceso continuo que se da en diferentes actividades en las que los sujetos tienen la oportunidad de relacionarse, consigo mismos y con otros. La educación, por su parte, tendría que promover unos valores familiares, culturales, sociales en los cuales se sostenga una determinada identidad; pero no son las familias, las escuelas, los maestros los que forman al sujeto; pues solo él mismo está en capacidad de formarse: tanto en su intimidad, en el encuentro consigo mismo, en el que, consciente de sí mismo, constituye sentido de sus vivencias; como en la intersubjetividad, en la vida comunitaria, en el diálogo con los otros:

De lo que se trata es del descubrimiento del sí mismo [énfasis del original]. Y esto sólo puede ser realizado por las vías de la investigación y por las vías de la educación. [...] la educación es la acción de una tercera persona que al dirigirse a una segunda persona propicia que ésta, en calidad de primera persona: potencie, despliegue y realice sus potencias anímicas. (Vargas Guillén, 2012, p. 50)

De otra parte, el "contenido" de la formación, ese en qué se forma el sujeto, no es un contenido al azar; este está determinado, idealmente, por la cultura, por la historia, por las familias, por las instituciones educativas, por las agrupaciones religiosas, etc., que, de alguna manera, ofrecen a los sujetos un ideal de formación; pero en la medida que cada sujeto es quien configura este ideal, y su correspondiente proyecto, el resultado de un proyecto de formación es individual, el resultado es cada individuo; es necesario, entonces, que cada quien se disponga hacia 
qué es lo que quiere o qué es posible formar de sí mismo. Esta disposición se logra, precisamente, en la interacción con los otros, en la configuración de sus propias pasiones, es decir, en la constitución de unidades de sentido que lo predisponen favorable o desfavorablemente a ciertas condiciones.

Un proyecto de formación puede valerse de una retórica en situación (cf. Vargas Guillén y Cárdenas Mejía, 2005, p. 21), de la construcción de discursos retóricos que propicien la configuración de las pasiones de los sujetos, que se promueva en ambientes de aprendizaje apropiados, en los que los sujetos se involucren, reflexionen acerca de sí mismos y de los otros, aprendan el respeto por las opiniones de los demás, en últimas, ambientes y discursos que hagan posible el aprendizaje y el despliegue de las estructuras argumentativas, mediante las cuales los sujetos se reconocen, reconocen a los demás y se forman a sí mismos.

La formación como proceso individual resultaría fallido en la medida que produzca sujetos "en serie", que respondan a una forma de ser predeterminada y uniforme, a un "tipo ideal" de sujeto, que no se ajusta a cambios del mundo, de las culturas y de las tecnologías.

Los proyectos de formación impactan a los sujetos de tal manera que sus efectos no necesariamente llegan a coincidir con un ideal propuesto. Es posible que los objetivos de tales proyectos educativos correspondan a necesidades construidas por las culturas, a ideales que por su misma condición ideal implican su imposibilidad. Tales necesidades, según el enfoque de G. Bustamante, son construidas, pues, no son del todo esenciales para los sujetos; son características contingentes adquiridas por ellos en el vivir de su propia cultura, arraigadas de tal manera que parecen necesarias, pero que no siempre lo son (cf. Bustamante Zamudio, 2006). Estos elementos culturales, en cuanto ideales, podrían representar para quien se está formando un mayor o menor grado de fracaso, lo que, posiblemente, le suma a esta compleja tarea una actitud de insatisfacción permanente.
Las instituciones educativas no son exclusivamente el lugar en el que se realiza la formación. Una multiplicidad de vivencias del mundo, de la vida cotidiana, ofrece permanentemente la posibilidad de reconocerse y de reconocer a los demás. Si, de una parte, las instituciones escolares no cuentan con ambientes que propicien la interacción, y de otra, no pueden predecir y menos intervenir las vivencias que sus estudiantes tienen fuera de ellas, ¿cómo diseñar proyectos de formación de valores que se aprenden, precisamente, en la interacción con los otros? ¿Cómo plantear proyectos de formación de ciudadanos aptos para la democracia, para ejercer una "ciudadanía del mundo"?

Las instituciones educativas están llamadas a plantear proyectos y a diseñar ambientes que ofrezcan a los sujetos la posibilidad de tener vivencias intersubjetivas en las que hagan valer sus puntos de vista y den sentido a su propia historia, a su cultura. Tales proyectos apuntarían a la formación de cada sujeto; es decir, a que cada quien se prepare para plantear sus propios proyectos, $y$, antes que todo, para "ser capaz de pensarse y significarse" (cf. Bustamante Zamudio, 2006); es decir, tener la capacidad de hacer valer sus valores, sus necesidades, sus fortalezas; y tener la capacidad de debatir, de argumentar consigo mismo y con los otros, proyectos individuales y colectivos.

Para Nussbaum, la educación de esta época debe ser multicultural, de manera que los estudiantes conozcan y respeten otras culturas, otras historias, otros valores, como

[...] verdadero sustento del diálogo. No existen fuentes más seguras de desprecio que la ignorancia y el sentido de la inevitable naturalidad del estilo propio de cada uno. Ninguna educación liberal puede ofrecer a los estudiantes un adecuado entendimiento de todo lo que deberían saber sobre el mundo; pero una comprensión profunda de alguna tradición desconocida, y algunos rudimentos sobre otras, bastarán para engendrar el conocimiento socrático de las propias limitaciones. (Nussbaum, 2001, pp. 101-102) 


\section{Argumentación y TIC}

La incursión de las Tecnologías de la Información y la Comunicación (TIC) en la vida de los sujetos ha hecho que los procesos argumentativos se den también en entornos mediados por tales tecnologías. Los medios escritos dan testimonio de formas de pensamiento a través de la historia y del mundo, dan a conocer discursos estructurados, que pueden ser revisados, deconstruidos y discutidos tanto por autores como por lectores. La lectura y la discusión de textos pueden propiciar el ejercicio del razonamiento y de la argumentación, es decir, su práctica, pero también su aprendizaje y su enseñanza:

Los libros, incluyendo algunos de los grandes textos del pasado cultural propio, pueden en efecto tonificar una mente perezosa, proporcionándole la información que necesita para razonar bien, así como ejemplos de una buena argumentación. El dominio de la lectura y escritura, incluyendo el conocimiento de textos culturales, confiere fuerza e independencia [...]. Trabajar con los argumentos contenidos en las obras maestras puede hacer más aguda la mente, más rigurosa, más activa. Esto garantiza que la mente cotejará un amplio abanico de opciones sobre las cuestiones importantes, y las cotejará de una manera desafiante, incluso allí donde la cultura popular es difusa y superficial.

(Nussbaum, 2001, p. 60)

Los media, como el cine, la radio, la televisión, la prensa, los comics, ofrecen representaciones gráficas, auditivas y textuales de la información, como otras formas de discurso, de pensamiento, otras formas de ver el mundo. Las TIC se han convertido en espacios que propician la interacción entre sujetos que no necesariamente están en el mismo lugar, que no necesariamente hablan el mismo idioma, que no están necesariamente al mismo tiempo comunicándose.

De los cuatro espacios antropológicos que propuso Lévy - la Tierra, el territorio, el espacio de las mercancías, el espacio del conocimiento-, el espacio del conocimiento está determinado por las posibilidades de agrupación, de comunicación y de participación que se derivan de la Internet en el ciberespacio, que, a diferencia de los medios, que son administrados por el "poder", ofrece la posibilidad de conformar las llamadas inteligencias colectivas, una forma de inteligencia "repartida en todas partes, valorizada constantemente, coordinada en tiempo real, que conduce a una movilización efectiva de las competencias", cuyo objetivo es "el reconocimiento y el enriquecimiento mutuo de las personas" (Lévy, 2004, p. 19).

En el arte, la televisión, los grafitis, la publicidad, los íconos gestuales hay estructuras argumentativas que dan cuenta de las técnicas, de las formas de representación del mundo, del lenguaje, de la cultura, de las emociones humanas, etc. Para cada forma de expresión es posible establecer cómo opera la semántica de sus mensajes, y cómo ellas promueven o no la difusión de temas, la generalización de opiniones, el desarrollo de un espíritu crítico, la comunicación entre grupos, entre generaciones, el abuso del poder, etc., por lo que podría considerarse que en cada forma de comunicación hay, de alguna manera, una forma de argumentación de la que es necesario comprender sus estructuras icónicas y semióticas, con el fin de plantear nuevas formas de educación de ciudadanos con espíritu crítico, preparados para discutir, para denunciar y para decidir sobre lo que le afecta directa o indirectamente, para responder a las necesidades de asociación en inteligencias colectivas.

Con independencia de la forma de discurso y de las estructuras argumentativas, son los sujetos los que procesan tales discursos mediante el razonamiento; para ello, la argumentación se constituye en una vía para el aprendizaje de procesos de pensamiento y para una formación en valores que ofrecen la posibilidad de enfrentar críticamente cualquier discurso. P. Lévy ha considerado el ciberespacio como el entorno más adecuado para desarrollar el espacio del conocimiento que hace posible la conformación de grupos en inteligencias colectivas, en la medida que propicia el intercambio de conocimiento, la construcción colectiva de sentido.

"El ciberespacio podría convertirse en el lugar de una nueva forma de democracia directa a gran escala" (Lévy, 2004, p. 43). Hoy, diez años después 
de que Lévy formulara esta sentencia, las llamadas redes sociales parecerían haberse convertido en ese ciberespacio, en cuanto permiten la conformación temporal de comunidades interesadas en temáticas, también temporales, tendencias o trendingtopics (TT), que determinan masivamente objetos de discusión, de indignación, de protesta o de diversión de los usuarios. Las redes sociales, como espacio de interacción, como punto de encuentro, constituyen para los usuarios lo que ellos mismos determinen mediante el sentido que les dan.

Así, por ejemplo, en la más reciente campaña presidencial en Colombia se sabe que la mayoría de las estrategias fueron concebidas sobre las redes sociales, con efectos tan favorables como adversos para los candidatos; estas consistieron, por ejemplo, en difundir rumores, en crear miles de cuentas de falsos usuarios que opinaban lo requerido por la campaña, en aprovechar videos y frases que se hubieran hecho populares; pero, por otra parte, los hechos ocurridos a diario daban lugar a discusiones entre ciudadanos no vinculados a las campañas, que permitieron, de alguna manera, tener una participación en la forma de acción política. Una y otra circunstancia dieron lugar a procesos argumentativos por parte de los ciudadanos, puesto que, en el primer caso, cada quien tendría que haberse preguntado por la plausibilidad del rumor y por la conveniencia de optar por estar a favor o en contra de cada candidato, y en el segundo caso, dado que tales discusiones se daban mediante intervenciones escritas, para participar era necesario hacer explícito cada argumento.

El ejercicio diario de la política de algunos senadores puede seguirse a través de sus cuentas en Twitter, en donde van publicando frecuentemente sus intervenciones, las intervenciones de otros senadores, ideas sobre nuevos proyectos, denuncias que requieren presión social, etc. Así, este ejercicio se enriquece de las intervenciones de seguidores y opositores, de manera que los ciudadanos pueden, potencial y realmente, ejercer control político sobre las actuaciones de los representantes a la Cámara y al Senado.

Este potencial puede ser capitalizado también en la educación y en la formación ciudadana. Se sabe que con las computadoras y con la Internet es posible llegar a más lugares e impactar a más personas; distribuir textos escolares, manuales, resultados de investigación; propiciar discusiones; hacer clases virtuales, a distancia. El uso de TIC en las aulas facilita el manejo y la presentación de información, permite diseñar objetos didácticos; facilita la comunicación entre educador y educandos; motiva la revisión de piezas multimedia con información relevante.

La interacción de sujetos en el llamado ciberespacio - no solo en entornos de aprendizaje- ha dado lugar a la conformación de la cibercultura como conjunto de técnicas, prácticas, actitudes, modos de pensar y valores que se desarrollan en el ciberespacio. Según P. Lévy, esta forma de cultura "podría convertirse en un medio de exploración de los problemas, de discusión pluralista, [...] [de] hacer visibles procesos complejos, de toma de decisión colectiva y de evaluación de los resultados cercanos a las comunidades en cuestión" (Lévy, 2004, p. 41). Así, las TIC más que herramientas de uso necesario son un espacio potencial de encuentro en el que se suspenden los intereses individuales, las jerarquías y el intercambio de bienes (materiales), y se privilegian los intereses comunes cuyo discernimiento está determinado por las formas de argumentación: "El uso socialmente más útil de la informática de comunicación es sin dudas de proporcionar a los grupos humanos los medios para mancomunar sus fuerzas mentales para constituir colectivos inteligentes y hacer vivir una democracia en tiempo real" (Lévy, 2004, p. 42).

La inteligencia colectiva no es, entonces, una forma de agrupación común o estándar, mediada por tecnologías; es, según Lévy, la forma de agrupación cooperativa que "debe ser concebida como un verdadero servicio público", pues ella abre las posibilidades a una verdadera forma de democracia, la democracia directa:

Un dispositivo de democracia directa en tiempo real en el ciberespacio permitiría a cada cual contribuir continuamente a elaborar y a refinar los problemas comunes, a introducir nuevas preguntas, a forjar argumentos, a enunciar y adoptar 
posiciones independientes unas de otras sobre una gran variedad de temas. (Lévy, 2004, p. 44)

\section{Conclusión}

La democracia como forma de gobierno y como forma de vida hace necesario formar ciudadanos con capacidades argumentativas que les permita asumirla como discusión pública. Esta formación podría orientarse a la llamada ciudadanía del mundo que exige la construcción colectiva de valores que promuevan el respeto por la cultura propia y las ajenas, que propicien el diseño de proyectos colectivos y política estatales. Esta formación tendría que buscar el aprendizaje de formas de pensamiento crítico, de manera que sus ciudadanos estén en la capacidad de comprenderse, de respetar las posturas ajenas y de adaptarse o enfrentar los constantes cambios tecnológicos, políticos, sociales y naturales del mundo actual.

La formación es el proceso mediante el cual los sujetos constituyen, para sí mismos, sentido del mundo, a partir de los valores que prevalecen en las sociedades, en las familias, en los círculos sociales, académicos, científicos, etc., al tiempo que, en cuanto le dan nuevos significados a estos valores, en la medida que se forman, transforman sus propios entornos e impactan sus propias culturas. La argumentación se convierte en una vía que ofrece a los sujetos la posibilidad de desarrollar las capacidades para que la formación de tales valores se haga mediante el ejercicio de la crítica, la autocrítica y el descubrimiento de sí mismos; así como los prepara para el ejercicio de la ciudadanía.

Los entornos virtuales o TIC, en cuanto posibilitan el desarrollo de habilidades argumentativas de los sujetos, se constituyen en ciberespacio, en escenarios en los que se encuentran con independencia del tiempo y el espacio geográfico, donde su identidad está determinada por los intereses que los llevan a hacer parte de tales comunidades virtuales. Adicionalmente, el modo en que se agrupan los sujetos en estos entornos impide, de alguna manera, que se establezcan jerarquías y poderes, y queda, entonces, la comunicación como eje cohesio- nador de estas comunidades. En la medida que esta comunicación tienda al discernimiento de asuntos comunes es necesario recurrir a la argumentación como mecanismo formal de presentación de ideas. No obstante, no puede considerarse cualquier intervención como una forma de argumentación; depende, precisamente, del sentido que cada sujeto le otorgue tanto al medio, como a los contenidos, como a las circunstancias, que una intervención se realice mediante estructuras argumentativas.

\section{Referencias}

Aristóteles (2005). Retórica [Q. Racionero, Trad.]. Madrid: Gredos.

Bustamante Zamudio, G. (2006). Los efectos de la formación en los sujetos. Cuadernillos del Seminario doctoral Formación y subjetividad, 7.

Derrida, J. (1997). Las pupilas de la universidad. El principio de razón y la idea de la Universidad. Recuperado de: http://www.jacquesderrida.com.ar/textos/universidad.htm.

Hessel, S. (2011). ¡Indignaos! Un alegato contra la indiferencia y a favor de la insurrección pacífica. Barcelona: Destino. Recuperado de http://profesorvargasguillen.files.wordpress.com/2011/02/indignaos-porstc3a9phane-hessel.pdf

Lévy, P. (2004). Inteligencia colectiva. Por una antropología del ciberespacio (F. Martínez Álvarez, Trad.). Recuperado el 26 de junio de 2007, de Organización Panamericana de la Salud: http://inteligenciacolectiva.bvsalud.org/public/documents/pdf/es/inteligenciaColectiva.pdf

Lyotard, J.-F. (2008). La condición postmoderna. Informe sobre el saber (Edición impresa: Madrid, Cátedra, 1987). Recuperado el 15 de junio de 2008, de: http:// www.uruguaypiensa.org.uy/imagnoticias/690.pdf

Nussbaum, M. C. (2001). El cultivo de la humanidad. Una defensa clásica de la reforma en la educación liberal. Barcelona: Editorial Andrés Bello.

Perelman, Ch. y Olbrechts-Tyteca, L. (2006). Tratado sobre la argumentación. Madrid: Gredos.

Sen, A. (2006). El valor de la democracia. Barcelona: El viejo topo.

Vargas Guillén, G., y Cárdenas Mejía, L. G. (2005). Retórica, poética y formación. De las pasiones al enti- 
Universidad Pedagógica Nacional

Facultad de Humanidades

mema. Bogotá: Universidad Pedagógica NacionalUniversidad de Antioquia.

Vargas Guillén, G. (2007). Formación y subjetividad. Bogotá: Universidad Pedagógica Nacional.

Vargas Guillén, G., Gamboa Sarmiento, S. C., y Reeder, H. P. (2008). La humanización como formación. La filosofía y la enseñanza de la filosofía en la condición postmoderna. Bogotá: San Pablo.

Vargas Guillén, G. (2012). Fenomenología, formación y mundo de la vida. Problemas teóricos y metodológicos de la fenomenología. Berlín: Editorial Académica Española. 